\title{
Renewable Energy Potentials along the Bay of Bengal due to Tidal Water Level Variation
}

\author{
Myisha Ahmad ${ }^{1, *}$, G. M. Jahid Hasan ${ }^{1}$, H. M. Mohaymen Billah Chy ${ }^{1}$, and Gazi Masud Md. Mahenoor ${ }^{1}$ \\ ${ }^{1}$ Department of Civil Engineering, Military Institute of Science and Technology (MIST), Dhaka, Bangladesh
}

\begin{abstract}
The projected increase in energy demand coupled with concerns regarding present reliance on fossil fuel and associated environmental concerns had led to increased interest in exploiting renewable energy sources. Among different renewable energy sources, tidal energy is unique and most suitable because of its predictable nature and capability to ensure supply security. Tide consists of both kinetic and potential energy which can be converted to electricity using well-proven technology. The potential energy of tides - the principal focus of the study, is stored due to rise and fall of the sea level. Head difference created due to tidal variation between basin side and sea side of a barrage stores potential energy which is converted into fast-moving water that rotates turbine and generates electricity. Bangladesh with its long coastline has promising prospects of tidal energy resource development. The study focuses on tidal energy resource exploration and exploitation along several competent locations of the Bengal coastline. Tidal records of flood and ebb tide of these locations are analyzed to calculate the potential energy. Finally, available potential techniques of energy extraction are evaluated for annually generated energy estimation. This study investigates the prospect and utilization of tidal energy concept and reviews the possibilities and opportunities of employment of the technology for sustainable development and climate change mitigation in context of Bangladesh.
\end{abstract}

\section{Introduction}

Energy is the pinnacle of human civilization. It is an indispensable input of survival for human. Currently, the consequence of the depletion and price fluctuation of the traditional energy resources are at the forefront of the global energy debate. Energy needs, their associated security of supply, coupled with environmental concerns and the impact of climate change requires constructive attempts to exploit non-polluting renewable energy sources. There is now an urgency to ensure sustainable development that will meet the demand of the present without reducing the ability to meet future demand. As per sustainable development goals 2030, the reliance on clean renewable energy resources has to be increased. The improved energy consumption efficiency and conversion measures have to be adopted to minimize the loss of primary resources without risking the climate. This has resulted in search of new energy generation methods with renewable sources which are promoted globally and therefore offer a window of opportunity for expanding utilization of renewable energy technologies through research and development activities.

Over the last thirty years, harnessing tides as a source of electric power have been a part of world trend that marks the introduction of renewable energy sources and the tapping of local potential for exploitation of these sources. There has been a concerted effort worldwide to make harnessing of renewable sources, particularly tidal power compatible with energy demands and environmental concerns. Tidal energy is unique because of its ability to provide predictable, clean power ensuring supply security. The tide and the resultant power is predictable and dependable, which makes the energy attractive in a future renewable weighted energy market when compared to wind and wave. The concept of conversion of tidal power for human use is very ancient, there being instances from Roman epoch describing its use for milling grain. Tide mills have also been used by the Spanish, French and British, date back to 787 A.D. In the Middle Ages tide mills have been used in Europe and Northern America [1]. The most recent endeavors at harnessing the tide have focussed on converting the hydraulic power of tides into electricity.

Currently, there are three major options for generating power from the tides: a barrage, a fence, and a tidal farm. The foremost method, which is the main focus of this study, is an efficient approach to power generation by placing a barrage across a tidal inlet. The barrage requires building a dam across an enclosed tidal basin. Sluice gates are employed along the structure that assists in filling the basin with the rising water level. The gates are then closed to 
develop a head difference and power is thereby generated through turbines with the falling of tides.

According to Rathod and Gaikwad [1], the first commercial-scale modern-era tidal power plant was built, near St. Marlo, France. In 1966, the first tidal barrage was completed in France with commercial level electricity generated by La Rance power station. Between 1966 and 2011 a number of small tidal plants were constructed in countries with an abundance of tidal energy resources namely, Canada, China, Iran, Russia, Korea, the UK, Mexico, Brazil, and India [2]. The largest and the newest tidal barrage in the world is the Sihwa dam in north-eastern South Korea, built in 2011 and operational from 2012. It is a multi-functional tidal barrage which prioritizes ecological water quality improvement.

In Bangladesh, Karnaphuly hydropower station is the only hydropower plant located at Kaptai, Chittagong having a capacity of $230 \mathrm{MW}$ where potential energy of stored water is used. But with an existing long coastline, coastal energy potentials have not yet been explored which can be a great source of sustainable renewable energy in order to meet future demand. However, fewer studies have been carried out to explore the potential of electricity generation from tides along the Bay of Bengal. Hossain et al. [3] studied the potentiality at Sandwip Channel with an average tidal range of $4.6 \mathrm{~m}, 23$ sluices and a barrage having the capacity to generate $16.49 \mathrm{MW}$ of electricity daily. However, none of these studies have been implemented practically till date at least to the author's knowledge.

In this paper, the main subject is to take a closer look at the potential of tidal energy resource along the Bay of Bengal. In addition, the work establishes a constructive approach that could be assisted for technology and project development aspects, through analysis of results based on experimental and field observations. The aim here is to highlight the future prospects of energy production utilizing the tidal resources, and also to project the approaches needed in the development phases of the technology; because tidal energy might be a vital, viable and reliable option of the future energy market.

\section{Tidal Energy}

\subsection{Origin of Tide}

Tides are caused by the gravitational pull of sun and moon on earth's oceans, coupled with the relative position of sun and moon and the rotational force of earth. The rise and fall of tides create potential energy while the flows due to flood and ebb currents create kinetic energy. Both of the energy forms can be harvested by tidal energy conversion technologies. This paper studies the former category that deals with the tidal range concept.

Tide cycles are calculated and can be predicted with high accuracy. It is possible to predict the tide levels of a particular location. The basic harmonic changes of tide level are also eminently predictable. Tide changes twice daily in the region where semidiurnal governs. The difference between the high and low tide is the tidal head available for each tide cycle. On a global scale, some tidal head is as small as 0.5 meter to some are as large as 12 meters [4]. Broad mouthed estuaries create larger tidal range than long straight coastlines. Tidal power is directly proportional to the square of the tidal range and hence higher tidal ranges are the most attractive location for tidal power generation.

\subsection{Energy Extraction Techniques due to Tide}

Tidal barrage technologies harvest the potential energy created by the difference in head between ebb tide and flood tide. Tidal barrages are built across suitable bay or estuary, are designed to extract this potential energy using turbines located inside the barrage. The potential energy caused by the water level difference across the barrage is converted into kinetic energy in the form of fast-moving water passing through the turbines. This, in turn, converted into rotational kinetic energy by the blades of the turbine. The spinning turbine drives a generator to produce electricity. The highest output is achieved by operating these turbines at the highest head. The highest head is available at extreme low tide or extreme high tide. The period of the high and low tide is roughly two hours but the half an hour before and after each high and low tide the water level does not change significantly. Thus a total generation period of three hours is achieved in each cycle in semidiurnal areas. Using the combination of flow direction through the turbine and arrangements of the pool commonly five different methods of power generation are employed, explained by Zabihian and Fung [4]. Brief of each of these methods are summarized as follows:

\subsubsection{Single Pool Ebb Type Generation}

This is a one-way generation method. Water flows from basin-side to sea-side. Power is generated during the low tide or ebb tide. The sluice side of the barrage is kept open during flood tide and the basin is allowed to fill. At the beginning, both the seawater and basin water will rise up to $\mathrm{M}$ as depicted in Figure 1. When the basin and seawater reaches the same level, both the sluice side and turbine portion of the barrage is kept close, till the 

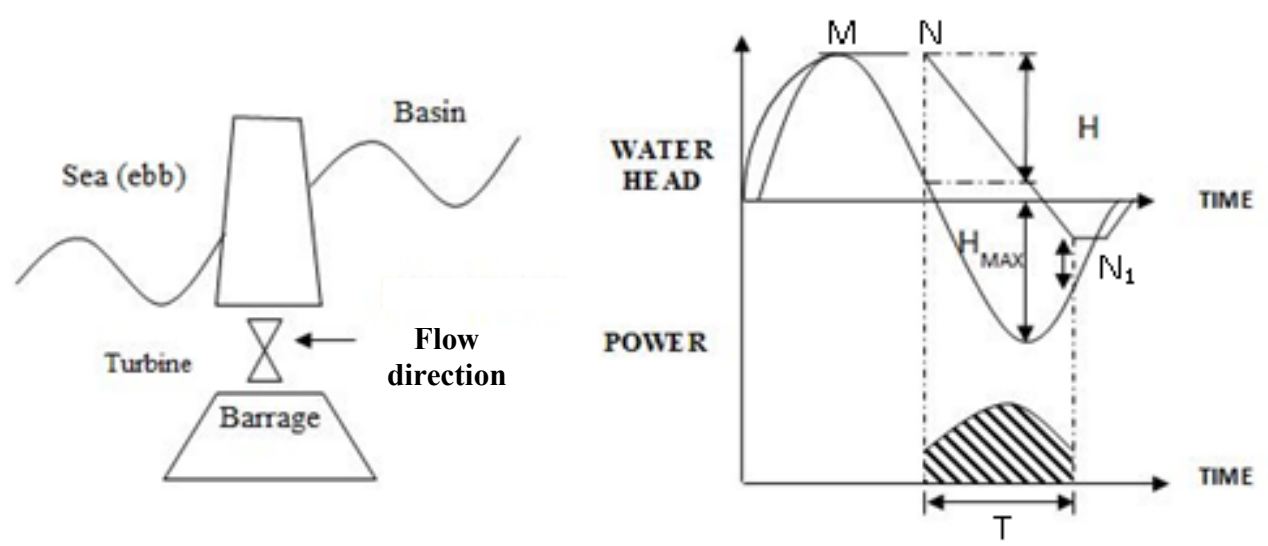

Fig. 1. Schematic diagram of a single pool ebb system.
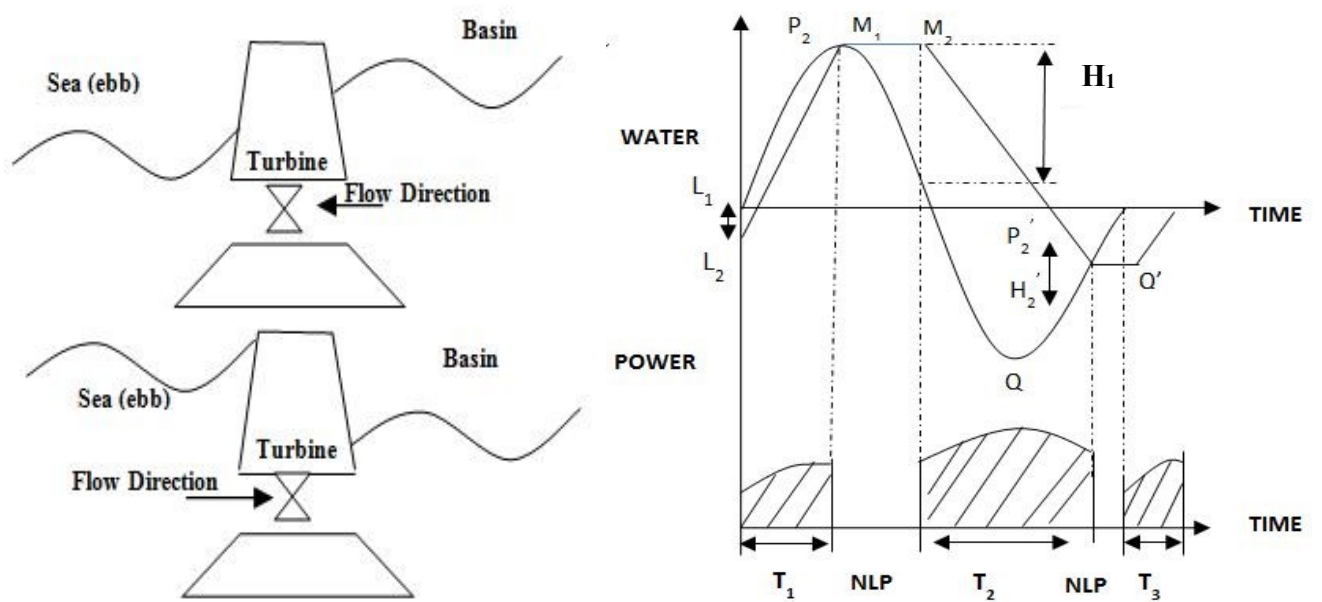

Fig. 2. Schematic diagram of a single pool two way (flood and ebb) system

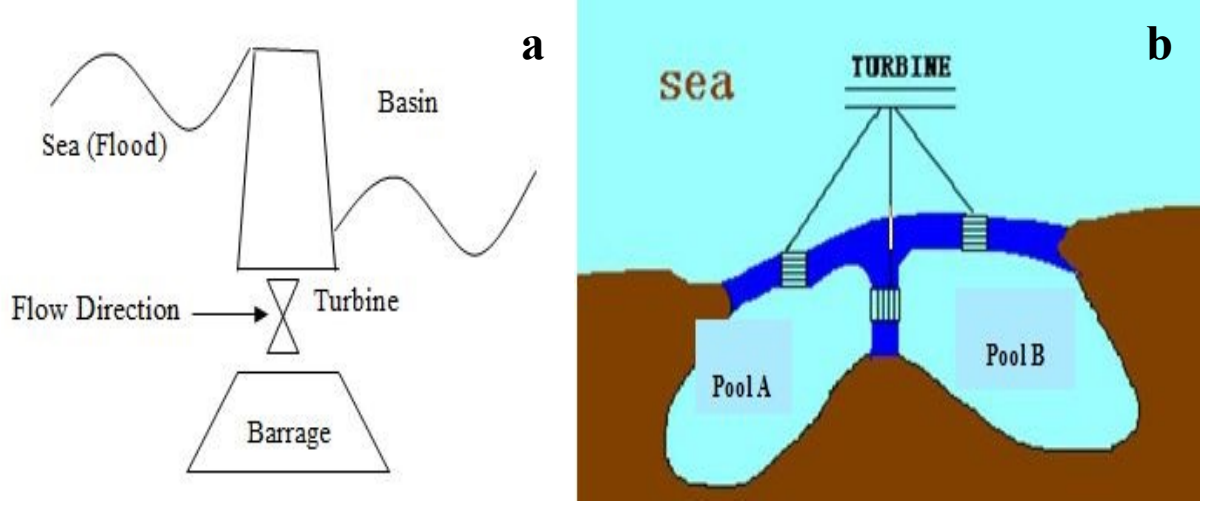

Fig. 3. (a) Single pool flood system and (b) two pools ebb and flood system.

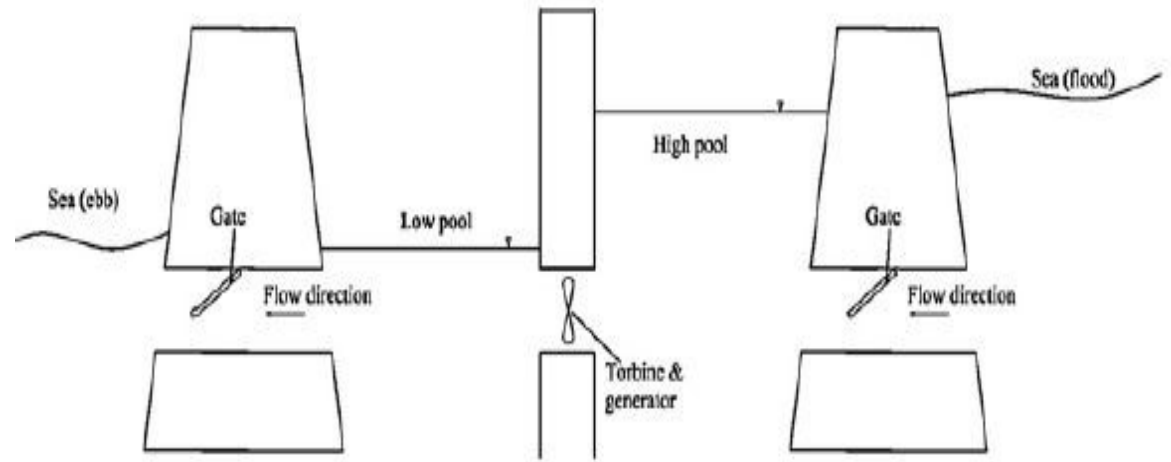

Fig. 4. Schematic diagram of a two-pools one-way system [4] 
seaside water level fall due to ebb tide and head $\mathrm{H}$ is created. When sufficient head is achieved the gates are opened at point $\mathrm{N}$. The water is allowed to pass through the turbines for the duration of $\mathrm{T}$ till the basin water level reaches point $\mathrm{N}_{1}$. At this point, both turbine and sluice are kept close, till the water levels on both sides are equal. The next cycle starts again when the water level is same on both sides of the barrage. This type of plant operates for five hours and remains off for seven hours in one cycle of the tide.

\subsubsection{Single Pool Flood Type Generation}

The single pool flood generation system is similar to the first one. The only difference in this mechanism is that the power is generated when the basin is filling. During the flood tide, the sluice gates and the turbines are kept close until a considerable head is formed. The sluice gates are then opened and water flows from the sea to basin (Figure 3a). Though the time period of the generation is almost same of the first method, the head difference is much less. As a result, power generation is lower than the first method.

\subsubsection{Single Pool Two-Way (both Flood and Ebb) System}

The third method uses the advantage of the bidirectional turbine. Electricity can be generated both during the flood tide while the basin is filling and during the ebb tide by emptying the basin. During flood, tidewater will pass through turbine and therefore there should be a head difference which is between point $\mathrm{L}_{1}$ and $\mathrm{L}_{2}$ (Figure 2). Eventually basin water level will level up with sea water level. At this point, no electricity will be generated. This time period is termed as No Load Period (NLP). This period will continue until sufficient head is built up due to falling of sea water level during ebb tide. At point $\mathrm{M}_{2}$, when sufficient head has built up and the gates of turbines are opened in the opposite direction and basin water will fall. The generation will last until point $\mathrm{P}_{2}{ }^{\prime}$, when the head difference is not sufficient to generate electricity. Turbines will be shut but sluice will remain open till point $Q$. Sluice gates will be closed at point $\mathrm{Q}^{\prime}$ when the water level will be same both at sea and basin side. After the next head difference is built, sluice gates open and next cycle begins. From the Figure it is obvious that total generation time is $T_{1}+T_{2}$, thus the total generation is higher than the previous two methods. Sometimes water is pumped from the sea to basin side keeping the sluice closed to increase the head and thereby the generation.

\subsubsection{Two Pool Ebb and Flood System}

This method is a combination of first two methods. Where one of the two pools operates based on the single pool flood type system and another operates based on the single pool ebb type system. Usually, turbines are places between pool A and pool B to generate additional power while transferring water from A to B as shown in Figure 3b. This type of generation produces more power than single pool flood or ebb type system. But this requires large basin area and a minimum three barrage needs to be constructed across the channel.

\subsubsection{Two Pools One-Way System (high and low pools)}

The fifth method needs two separate physically adjacent pools i.e. high and low pools. The high pool is filled during the flood tide. The low pool is emptied on the other side during ebb tide. Power is generated during the transfer of water from the high pool to low pool through the turbine (Figure 4). This type of generation plant can generate power almost continuously, and the NLP becomes very short. It requires estuary or bays with very high tidal range. Sites with such requirements are very limited around the world.

\section{Study Location}

Bangladesh has a long coastline of $710 \mathrm{~km}$ with an average tidal variation of $2 \mathrm{~m}$ to $5 \mathrm{~m}$ [5]. A number of potential locations along the coast are suitable to be used as basin areas. Generally, sites having the high tidal range and large basin with a narrow mouth are preferred for barrage construction. For this study, total seven tide stations were selected along the coastal area stretching from Saint Martin to Hiron Point. Locations are displayed in Figure 5. The stations Hiron Point, Khepupara and Charchanga are surrounded by several tidal rivers, creeks and are located near the Sundarban region. The location of Hiron Point is near the mouth of Pussur River. Khepupara is located in the shallow region near west of Dimer Char and Pokhkhir Char. Charchanga is at the mouth of Meghna River on the western side of Hatiya Island and surrounded by a group of small islands. Jahaizzer Char is a newly developed island located near Swandip and has two distinct channel in its east and west side. The tide station at Cox's Bazar is nearly $10 \mathrm{~km}$ offshore from Mahes-Khali channel, and Saint Martin is located on the southern tip of Bangladesh. In these locations, the tidal range varies from $5 \mathrm{~m}$ in monsoon to $2 \mathrm{~m}$ in dry season on an average scale. All these selected seven sites have deep channels with a moderate basin area and narrow mouth for easier construction of tidal barrages.

\section{Generation of Energy}

\subsection{Energy Estimation}

Harnessing energy through construction of a barrage and creating a reservoir has a principle very similar to conventional hydroelectric project installed in any 
river. According to Tousif and Taslim [6], mathematically, average potential energy E due to the height difference of flood and ebb tide in each tidal cycle for a single pool ebb type or flood type generation can be calculated using the following equation:

$$
E=1 / 2 \rho g A H^{2}
$$

where $\rho$ is the density of the sea water in $\mathrm{Kg} / \mathrm{m}^{3}$, $\mathrm{g}$ is the acceleration due to gravity in $\mathrm{m} / \mathrm{s}^{2}, \mathrm{~A}$ is the basin surface area in $\mathrm{m}^{2}$, and $\mathrm{H}$ is the water level difference between flood and ebb tide in $\mathrm{m}$.

\subsection{Data Collection and Analysis}

Tidal records of the aforementioned seven stations for the year 2014 were collected from different organizations that maintain and operate tidal gauges at those locations, i.e. Bangladesh Water Development Board (BWDB), Port Authority Chittagong (PAC), Bangladesh Navy Hydro-graphic and Oceanographic Centre (BNHOC). Hourly tidal data was first filtered into daily high tide and low tide. Difference between the highest high tide and lowest low tide is the tidal range of a particular site for a particular day. The annual mean of these daily data was finally considered as the tidal range of a particular location. Moreover, based on the criteria of wider basin area and narrow channel mouth, the selected sites were analyzed through satellite images using Arc GIS and thereby, the probable basin area and barrage length was estimated. This area of the reservoir was used in energy calculation using Equation [1]. The basin areas are highlighted in Figure 6. The maximum area, thereby maximum generated power was obtained for Jahazzer Char West among the seven study locations. Figure 7 projects a graphical representation of the change of generated energy with a daily variation of tidal range, for Jahazzer Char West.

The tidal range data of the selected locations are used to estimate energy generation following one- way generation method. The main reason for selecting this method is that it provides a more effective method of generation with simpler equipment and easier installation. It is the most widely experimented method and most commonly used technology among the existing plants. Moreover, suitability of the method in the selected locations also influenced the preference.

\section{Results and Discussion}

As previously mentioned, in order to estimate the average power output of potential locations of the Bay of Bengal, one-way power generation method has been used. The annual mean difference of daily high and low tide is calculated to find the tidal range $\mathrm{H}$. The basin area A is calculated with the help of Arc GIS and these values are then incorporated into Equation [1] to estimate the energy generated due to water level variation from the tide. This energy per lunar day ( $24 \mathrm{hr}$ or $86400 \mathrm{sec}$ ) measures the generated power $\mathrm{P}_{\text {actual }}$ for one-way power generation method using the following equation.

$$
\begin{aligned}
& P_{\text {max }}=\frac{2 \times 1 / 2 \times \rho \times g \times A \times H^{2}}{86400} \\
& P_{\text {actual }}=\eta \times P_{\text {max }}
\end{aligned}
$$

where $\mathrm{P}_{\max }$ is the maximum power generated by the tidal turbine for one-way power generation method and $\eta$ is the coefficient of turbine efficiency which has been considered as $75 \%$ for this study. Table 1 illustrates the annual average power generation for the year 2014 in the selected seven sites.

It is observed that the tidal range reduces gradually from eastern part to the western part of the coast. Saint Martin and Cox's Bazar has a high tidal range of $2.22 \mathrm{~m}$ and $2.54 \mathrm{~m}$ respectively, but the

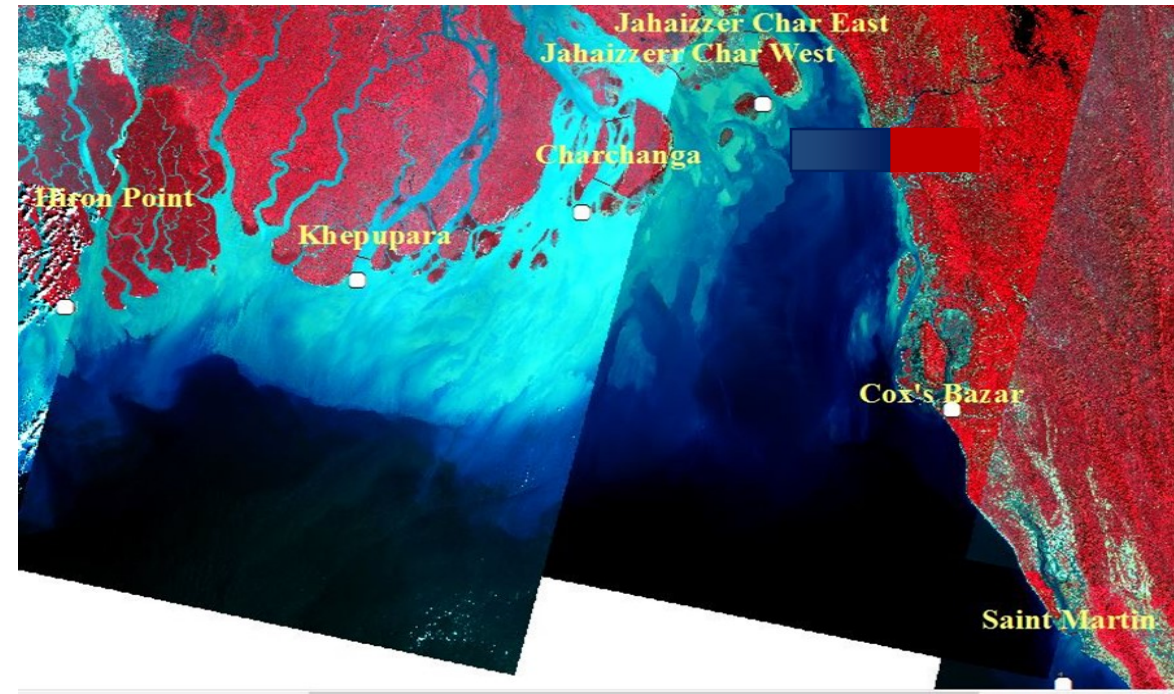

Fig. 5. Study locations along the coastline of Bangladesh considered for energy estimation. 

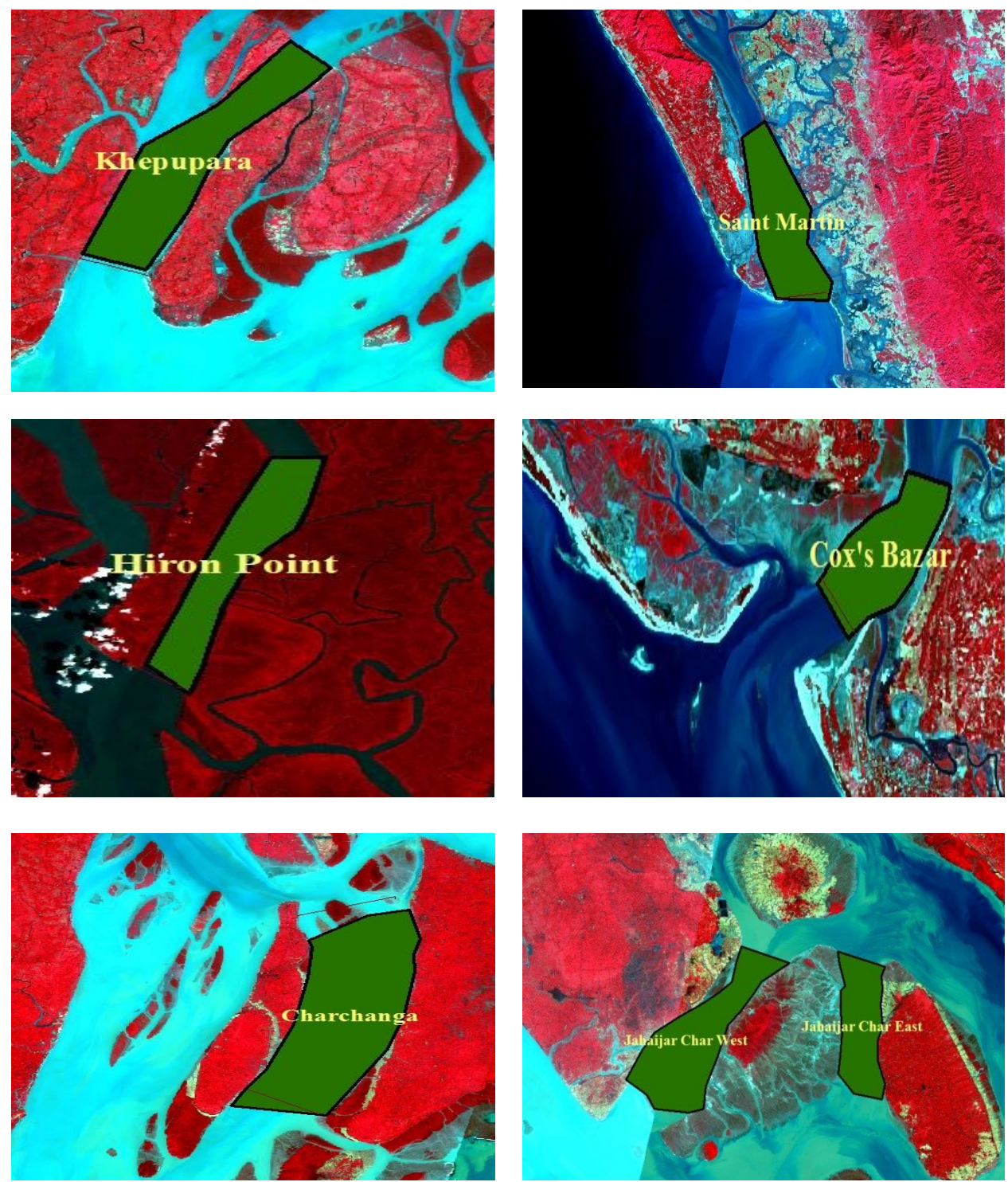

Fig. 6. Basin areas of all study sites based on the satellite image of November 2014.

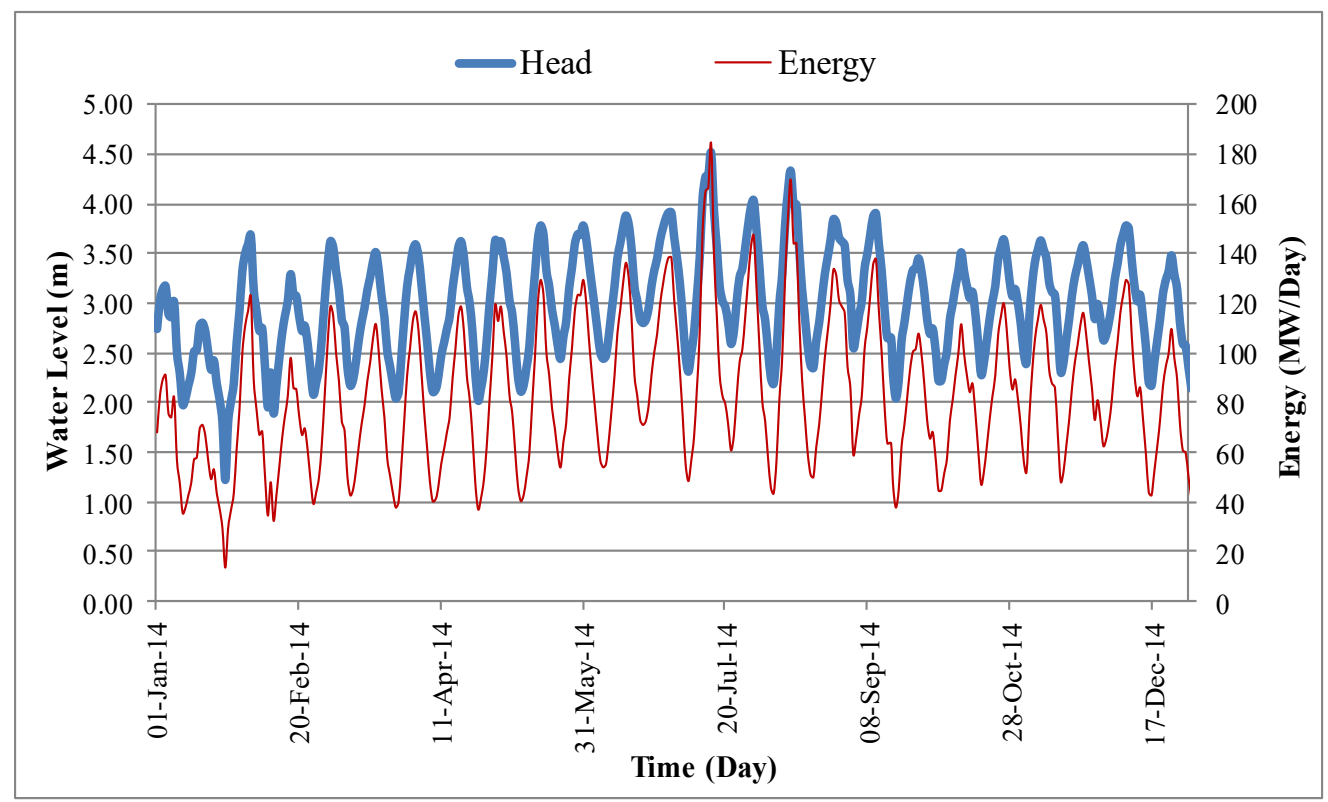

Fig. 7. Variation of daily tidal water level and estimated energy of Jahazzer Char East for the year 2014. 
Table.1. Summary of the generated annual energy at the study sites.

\begin{tabular}{|c|c|c|c|c|c|c|}
\hline $\begin{array}{c}\text { Serial } \\
\text { No }\end{array}$ & Station Name & Latitude & Longitude & $\begin{array}{c}\text { Tidal } \\
\text { Range, } \\
\mathrm{H}(\mathrm{m})\end{array}$ & $\begin{array}{c}\text { Basin } \\
\text { Area, A } \\
\left(\mathrm{km}^{2}\right)\end{array}$ & $\begin{array}{c}\text { Annual } \\
\text { Average } \\
\text { Power } \\
\text { Generation } \\
(\mathrm{MW})\end{array}$ \\
\hline L1 & Saint Martin & 20.59583 & 92.331388 & 2.22 & 38.13 & 18.1 \\
\hline L2 & Cox's Bazar & 21.439464 & 92.007732 & 2.54 & 90.26 & 55.04 \\
\hline L3 & $\begin{array}{c}\text { Jahaizzer } \\
\text { Char West }\end{array}$ & 22.37436 & 91.449405 & 2.94 & 103.66 & 80.73 \\
\hline L4 & $\begin{array}{c}\text { Jahaizzer } \\
\text { Char East }\end{array}$ & 22.37436 & 91.449405 & 2.94 & 60.5 & 47.06 \\
\hline L5 & Charchanga & 22.03662 & 90.92496 & 2.41 & 159.2 & 84.65 \\
\hline L6 & Khepupara & 21.81791 & 90.279263 & 2.05 & 68.3 & 28.2 \\
\hline L7 & Hiron Point & 21.72046 & 82.432934 & 2.04 & 35.8 & 13.78 \\
\hline
\end{tabular}

locations are remote and grid connectivity will be difficult. Charchanga has a large basin area and moderate tidal range of $2.41 \mathrm{~m}$. The tidal range of Hiron Point and Khepupara is low $(2.04 \mathrm{~m})$ and not suitable for an effective generation. Jahaizzer Char shows greater potentiality with a large basin area of $103.66 \mathrm{~km}^{2}$ on the west part and a highest tidal range compared to the other stations. A maximum generation of $80.73 \mathrm{MW}$ is obtained for this location considering an efficiency of $75 \%$. The newly formed island has two deep channels in its east and west side. The channel has a narrow mouth and is suitable for barrage construction.

\section{Concluding Remarks}

In response to the growing concern of reduction in worldwide fossil fuel availability and impacts of climate change due to greenhouse effects and carbon emission, it is time to stimulate the society to alter energy policy towards renewable energy sources. Energy generation from renewable sources is a clean and environmentally efficient method. Though the generation capacity is not as high as other generation methods, the main advantage is that the resources are infinite.

Tide is one of the few clean energy resources which is predictable with high accuracy and thus allows a finite amount of daily supply to be firmly contracted. This paper briefly outlined the status of tidal range technology potentials along the Bay of Bengal. The analysis of tidal records of seven suitable locations along the coast shows that there are several sites available along the coastline with a tidal range of 2-3 m. Considering easier installation, costeffectiveness, suitability in study area, one directional generation method is used for energy generation. Few sites like Charchanga and Jahaizzerchar has an annual average output up to 80 MW. It is observed that the tidal range is greater on the south-east part of the coast and gradually reduced to the western part of the coast. The tidal range of Saint Martin and Cox's Bazar is considerable but the absence of suitable basin location, also the locations being far away from grid connections, will increase the cost of connectivity with the grid. Charchanga has a larger basin area available and Khepupara and Hiron Point has narrow channel mouth but the tidal range varies very little in these locations. Jahaizzer char possess greater potentiality $(80.73 \mathrm{MW})$ in terms of higher tidal range, large basin area, and narrow channel mouth. These locations show better potentiality of electricity generation from tide and thereby secure optimistic opportunities for marine renewable resources.

\section{Nomenclature}
A $=$ Basin surface area $\left(\mathrm{m}^{2}\right)$
$\mathrm{E}=$ Energy generated from tidal turbines (Joule)
$\mathrm{H}=\mathrm{H}$ is the water level difference between flood and ebb tide (m)
$\mathrm{P}_{\text {actual }}=$ Power generated by tidal turbine for one- way generation method (Watt)
$\mathrm{g}=$ Acceleration due to gravity $\left(\mathrm{m} / \mathrm{s}^{2}\right)$
$\eta \quad=$ Turbine efficiency
$\rho \quad=$ Sea water density $\left(1025 \mathrm{~kg} / \mathrm{m}^{3}\right)$ 


\section{References}

[1] G. J. Rathod, and G. R. Gaikwad, "Tidal Power Energy- A renewable energy in future", ARD IJEET, 3(3), (2015).

[2] L. Hammar, J. Ehnberg, A. Mavume, B. C. Cuamba, and S. Molander, "Renewable Ocean Energy in the Western Indian Ocean", $J$. Renewable and Sustainable Energy Rev., 16(7), Pp 49384950, (2012).

[3] Md. A. Hossain, Md. Z. Hossain, and Md. A. Rahman, "Perspective and Challenge of Tidal Power in Bangladesh", International Journal of Electrical, Computer, Energetic, Electronic and Communication Engineering, 8(7), Pp 1140-1143, (2014).

[4] F. Zabihian, and A. S. Fung, J. Renewable and Sustainable Energy Rev., 15(5), Pp 2461-2474, (2011).

[5] L. Rose, and P. K.Bhaskaran, "The Role of Environmental Forcing on Tidal Dynamics along Complex near-Shore Waters off Bangladesh", J. Ocean Eng., 116, Pp 68-81, (2016).

[6] S. Md. R. Tousif, and S. Md. B. Taslim, “ Tidal Power- an Effective Method of Generating Power", IJSER, 2(5), (2011). 